\title{
Synthesis, Characterization and Photophysical Analysis of CDS Nanoparticles
}

\author{
Sundaravel Balachandran, Ponnuchamy Singannan, Anushiya Thiraviam
}

\begin{abstract}
The CdS quantum dots are prepared in AOT reverse micellar self-assemblies. The quantum dots were prepared from different precursor ratios of 1:1 and 1:2 which yielded different particle size. Steady state luminescence quenching studies were carried out for these quantum dots with $\mathrm{N}, \mathrm{N}$-dimethyl amine and triethyl amine. The downward curvature was observed form the SternVolmer plots showing the static nature of the quenching process. The static nature is attributed to presence of the quencher molecules to the quantum dot surface.
\end{abstract}

Keywords- Quantum dots, CdS nanoparticles, reverse micelle, luminescence, micro-emulsion.

\section{INTRODUCTION}

Semiconducting nanoparticles have been investigated intensively for their optical properties. These particles are called quantum dots, because quantum effects become important in these three dimensionally confined particles.

One of the exciting uses of quantum dots is as chromophores for biotags, where dots of different size are functionalized to detect different biological analytes. The researchers are much interested in studying the optical and electronic properties of quantum dots (QDs) (1-4). Cadmium sulphide QDs stood among the other QDs because of their unique properties (5-8). Researchers report a variety of techniques to synthesize CdS QDs. (9-11). Dannhauser et al claimed that the amine species interact with surface defect sites and enhance the luminescence of the QDs (12). Logunov et al demonstrated the relaxation dynamics of CdS QDs. They concluded that electron trapping in these QDs occur slowly when compared to hole trapping (13).

Bhargava and Gallagher studied the influence of manganese in the optical properties of $\mathrm{ZnS}$ nanocrystals. They reported that the small size manganese doped $\mathrm{ZnS}$ nanocrystal is responsible for the appearance of unique luminescence behaviour of the QDs. (14). Similarly Bhargava also concluded that the presence of desired impurities in the QDs enhance the luminescence properties by reducing the non-radiative recombination at the surface (15).

Narayanan et al reported the size of the CdS QDs influence the luminescence properties (16). Similarly Yang et al

Revised Manuscript Received on December 15, 2019.

* Correspondence Author

Sundaravel Balachandran*,Department of Chemistry, Kalasalingam Academy of Research and Education, Krishnankoil, India. Email: sundaravel.b@klu.ac.in

Ponnuchamy singannan, Alivira Animal Health Ltd., Parvada Mandal, Visakhapatnam - 531019, Andhra Pradesh, India. Email: ponnuchamy_85@yahoo.co.in

Anushiya Thiravium, Department of Chemistry, Kalasalingam Academy of Research and Education, Krishnankoil, India. synthesized ZnS nanocrystals inside a polymer matrix and claimed that the $\mathrm{ZnS}$ nanocrystals have better stability (17). Several reports were claimed the application of CdS, CdSe and CdTe QDs as light emitting diodes (18-21). Inverse (W/O) microemulsion have been successfully used as reaction media to synthesize monodisperse nanoparticles, semiconductors, cathode materials for lithium batteries and complex metal oxides $(22,23)$. Dazhen and co-workers reported the synthesis of $\mathrm{CdS} /$ polystyrene nanocomposite hallow sphere (24).

The semiconductor quantum dots (QDs) can be used as a promising components in optoelectronic devices (for example, in photovoltaic devices) and as tags for bio imaging, labelling, and sensing because of their pytophysical properties. However, these QDs suffer luminescence quenching and by amine like molecules hinders their application with biomolecules. In order to understand the stability of the nanoparticles with these quencher molecules and imparting this knowledge in preparing more stable nanoparticles the luminescence quenching studies are carried out. The quantum dots prepared in reverse micellar system are more stable when compared to the bare quantum dots. The interaction of the quencher molecules with the quantum dots in these stabilising agents are well studied in the current work.

\section{MATERIALS AND METHODS}

\section{A. Materials}

Cadmium nitrate (Merck) and Sodium sulphide nonahydrate (Merck), Bis (2-ethyle hexyl) sulfosuccinate sodium salt (AOT) (Fluka), Heptane (Qualigens), N, Ndimethyl aniline (Merck) and triethyl amine (Merck) were used in the CdS nanoparticle synthesis. All the reagents are analytical grade and used as such without any further purification.

\section{B. Synthesis of cadmium sulphide nanoparticles}

Cadmium sulphide nanoparticles (with 1:1 precursor ratio) were synthesized using the reverse-micelle method by adopting the procedure in the literature $(21,30)$. In a typical experiment, $5 \mathrm{ml}$ of $0.1 \mathrm{M}$ AOT solution was prepared in hexane in two separate polypropylene bottles and labelled as bottle A and bottle B. Exactly $36 \mu \mathrm{L}$ of $0.2 \mathrm{M}$ cadmium nitrate solution was added to the AOT solution in bottle A and $36 \mu \mathrm{L}$ of $0.2 \mathrm{M}$ sodium sulphide solution was added to the AOT solution in bottle B. The solutions in bottle A and B were stirred for one hour. Then the two solutions were mixed well and stirred for another one hour. 
Then the solution was allowed to stand. Similarly, CdS nanoparticles with 1:2 precursor ratios also synthesized.

\section{Quenching studies on cadmium sulfide nanoparticles}

In a clean and dry $50 \mathrm{ml}$ standard measuring flask about $2.36 \mathrm{~g}$ of $\mathrm{N}, \mathrm{N}$-dimethylaniline (DMA) was taken and dissolved in dodecane. Then the solution was made up to the mark to obtain 0.39 M DMA solution. Similarly 0.78 M DMA solution was prepared by dissolving $4.73 \mathrm{~g}$ of DMA in $50 \mathrm{ml}$ dodecane. $0.358 \mathrm{M}$ and $0.717 \mathrm{M}$ Triethylamine (TEA) solution also prepared by dissolving $1.812 \mathrm{~g}$ and $3.624 \mathrm{~g}$ of TEA in docdecane respectively. These solutions are used as stock solution and used for the quenching studies. To study the quenching effect of the amines, different concentration of amines were prepared from the stock solution and added to the $2.5 \mathrm{ml}$ of $\mathrm{CdS}$ nanoparticles solution.

\section{Methods}

Absorption spectra were recorded using Agilent 8453A UV -Vis diode array spectrophotometer. Fluorescence spectral measurements were carried out using a Perkin-Elmer MPF-44B fluorescence spectrophotometer interfaced with PC through RISHCOM-100 multimeter.

\section{RESULTS AND DISCUSSIONS}

CdS quantum dots were synthesized by reverse micellar method, where $\mathrm{Cd}^{2+}$ and $\mathrm{S}^{2-}$ ions are prepared separately in AOT reverse micelle. Then both the solutions are mixed together to form $\mathrm{CdS}$ quantum dots. These quantum dots are formed in the aqueous core of the reverse micelle. The synthesis was carried with different precursor ratio to yield CdS quantum dots of different sizes.

\section{A. Adsorption and emission studies}

The absorption spectra of CdS quantum dots prepared with different precursor ratios is given in the figure 1 . The $\mathrm{CdS}$ quantum dots prepared from 1:1 precursor ratio showed an absorption peak between 450 and $410 \mathrm{~nm}$ with a peak maximum centred at $420 \mathrm{~nm}$. Whereas the CdS quantum dots prepared from 1:2 precursor ratio showed a red shift and the absorption peak appeared at $450 \mathrm{~nm}$. This clearly showed that as the sulphide precursor ratio increases the particle size increases resulting in a red shift. The emission spectra of $\mathrm{CdS}$ quantum dots prepared with different precursor ratios is given in the figure 2. The emission spectrum showed peak maximum around $440 \mathrm{~nm}$ which is assigned to the band edge emission of CdS quantum dots.

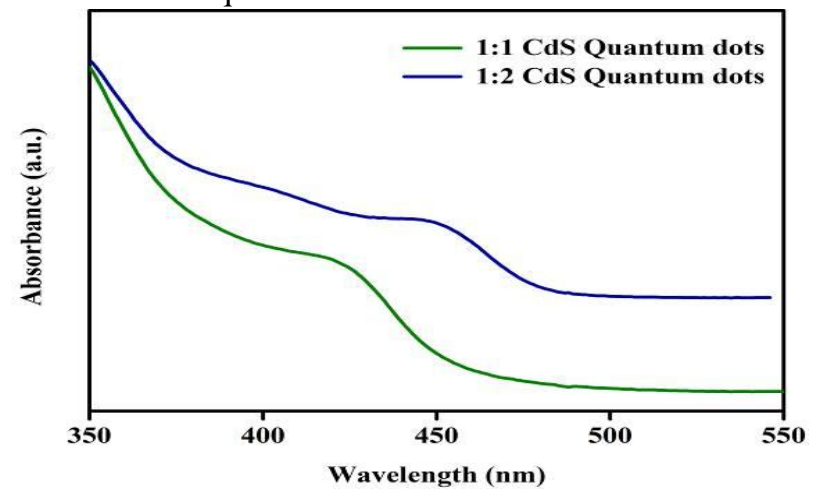

Fig. 1. Absorption spectra of CdS quantum dots

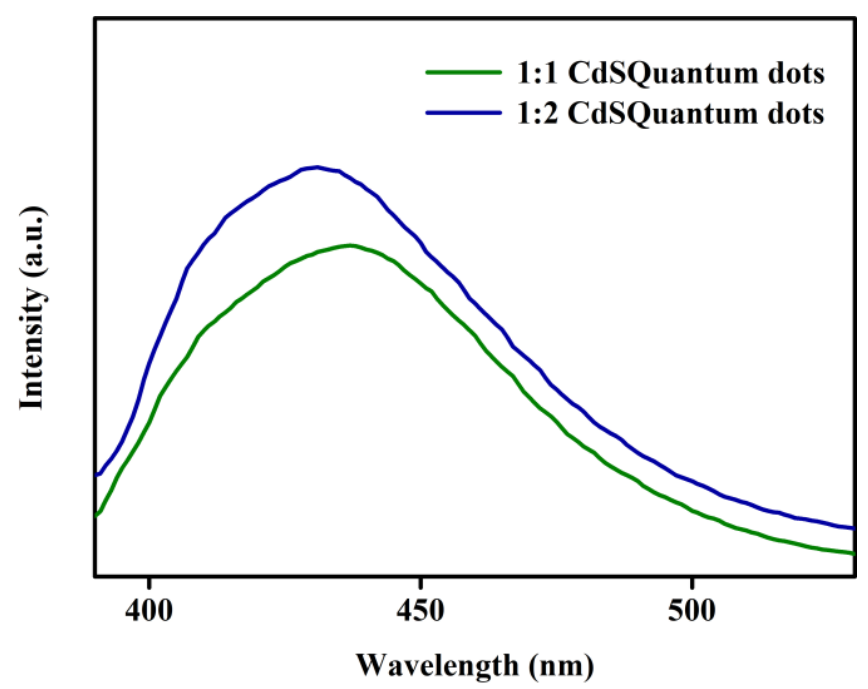

Fig. 2. Emission spectra of CdS quantum dots

B. Luminescence quenching studies of cds quantum dots

a. Absorbance in the presence of $\mathbf{N}, \mathbf{N}$ - dimethyl aniline (DMA)

The CdS quantum dots prepared from 1:1 precursor ratio was mixed with DMA solution of different concentration and their absorbance spectrum was recorded. Thus recorded absorbance spectrum is shown in figure 3 . There is no change in the absorbance value as the concentration of the quencher is increased which can be attributed to the absence of ground state complex between the quantum dots and the quencher molecules.

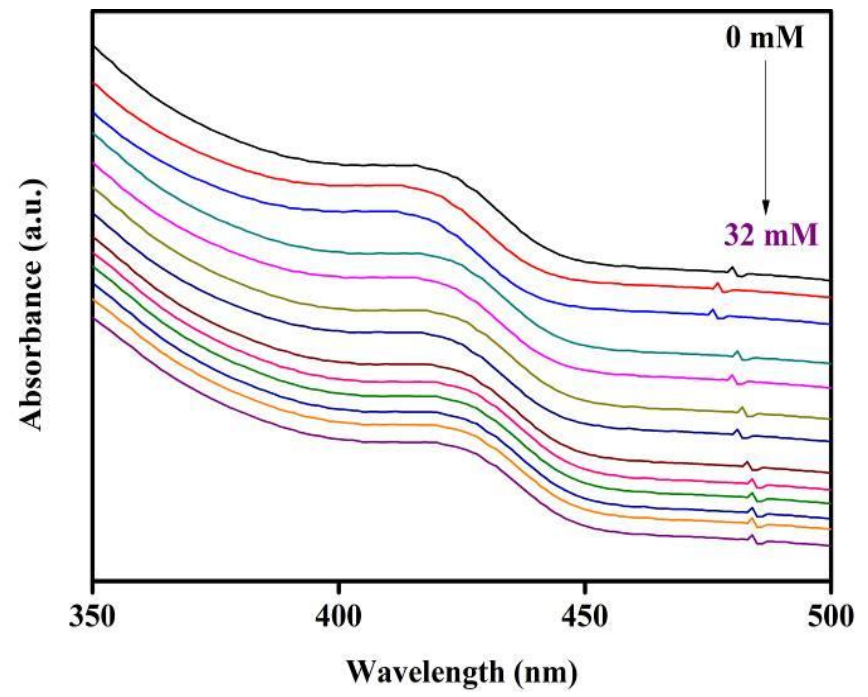

Fig. 3. Absorbance spectra of 1:1 CdS quantum dots in AOT reverse micelles with various concentrations of $\mathbf{N}$, $\mathrm{N}$, dimethyl aniline. The concentration values are $0,1.57$, 3.15, 4.77, 6.31, 7.88, 9.44, 11.04, 12.6, 14.2, 15.8, 25.2, $31.5 \mathrm{mM}$ (Top to Bottom concentration increases)

b. Absorbance in the presence of trimethylamine (TEA)

The CdS quantum dots prepared from 1:1 precursor ratio was mixed with TEA solution of different concentration and their absorbance spectrum was recorded. Thus recorded absorbance spectrum is shown in figure 4 . 
The spectra clearly indicated the TEA molecules didn't form any complex with the $\mathrm{Cd}$ species because the absorbance value doesn't vary when the concentration of TEA molecules is increased.

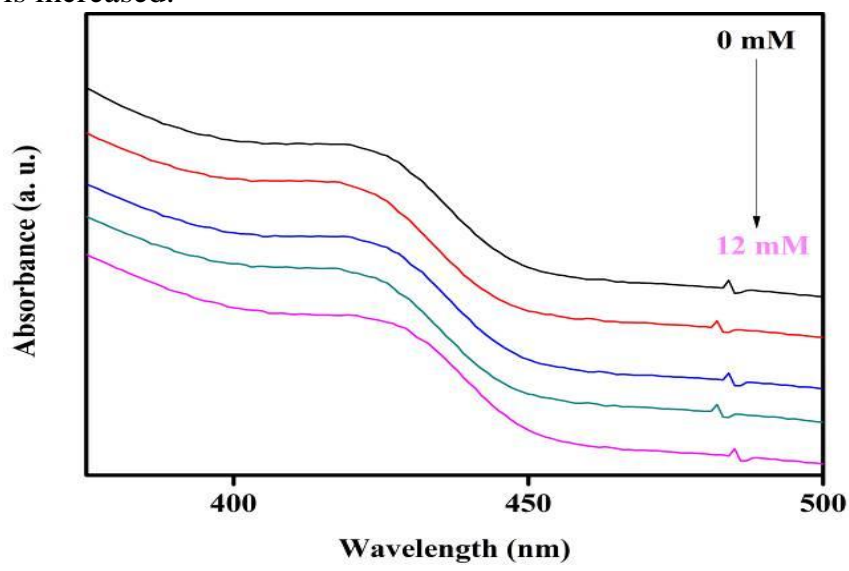

Fig. 4. Absorbance spectra of 1:1 CdS quantum dots in

AOT reverse micelles with various concentrations of triethyl amine. The concentration values are $0,2.87,5.73$, 8.60, $11.5 \mathrm{mM}$

c. Luminescence emission in the presence of DMA

Emission quenching studies were carried out for $\mathrm{CdS}$ quantum dots with $\mathrm{N}, \mathrm{N}$-dimethyl aniline. The emission spectra of CdS quantum dots (1:1 precursor ratio) with various concentration of $\mathrm{N}, \mathrm{N}$-dimethyl aniline is shown in figure 5. The emission spectrum shows decrease in the emission intensity as the concentration of the quencher is increased. The Stern-Volmer plot was constructed to calculate the Stern-Volmer constant. $\mathrm{I}_{0} / \mathrm{I}$ values showed downward curvature when plotted against the quencher concentration. The downward curvature in the Stern-Volmer plot is characteristic of the static nature of the quenching process. This type if static behavior is seen when the quencher molecules are present near the acceptor molecule, in the case of quantum dots the quencher molecules are possibly adsorbed on the surface or present in the near vicinity of the surface. This leads to the downward curvature in the Stern Volmer plot. The Stern-Volmer plot is given in figure 6 .

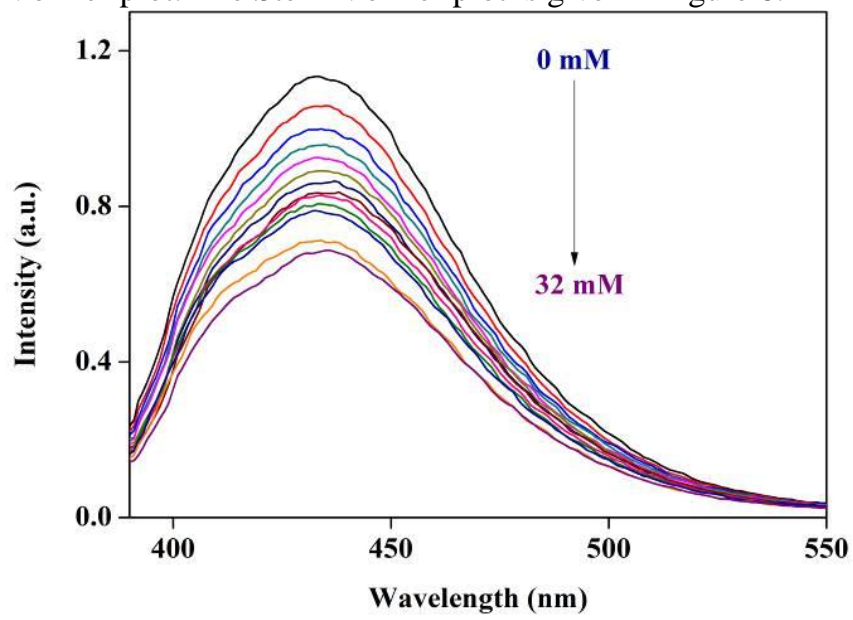

Fig. 5. Luminescence emission spectrum of 1:1 CdS quantum dots in AOT reverse micelles with various concentrations of $N, N$, dimethyl aniline,

The concentration values are $0,1.57,3.15,4.77,6.31,7.88$, 9.44, 11.04, 12.6, 14.2, 15.8, 25.2, $31.5 \mathrm{mM}$

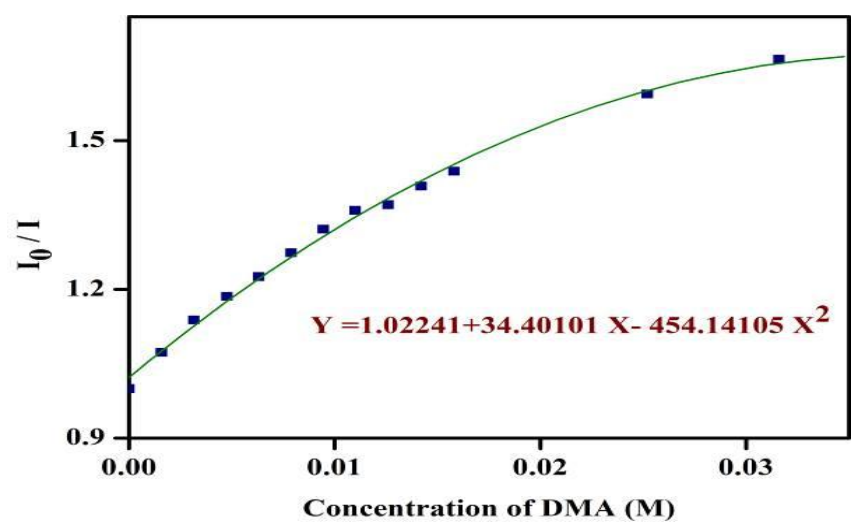

Fig. 6. Stern-Volmer plot of 1:1 CdS quantum dots in AOT reverse micelles with $\mathrm{N}, \mathrm{N}$-dimethyl aniline

\section{d. Luminescence emission in the presence of TEA}

The luminescence quenching studies were carried out with triethyl amine. Quenching in the luminescence emission intensity was observed when the concentration of triethyl amine was increased which is shown in figure 7.

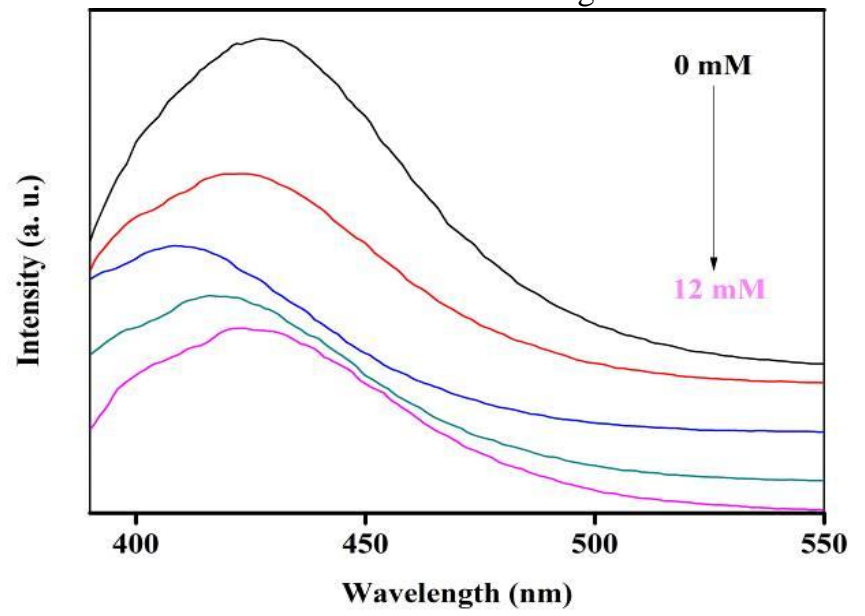

Fig. 7. Luminescence emission spectrum of 1:1 CdS quantum dots in AOT reverse micelles with various concentrations of triethylamine. The concentration values are $\mathbf{0}, 2.87,5.73,8.60,11.5 \mathrm{mM}$ (Top to Bottom concentration increases)

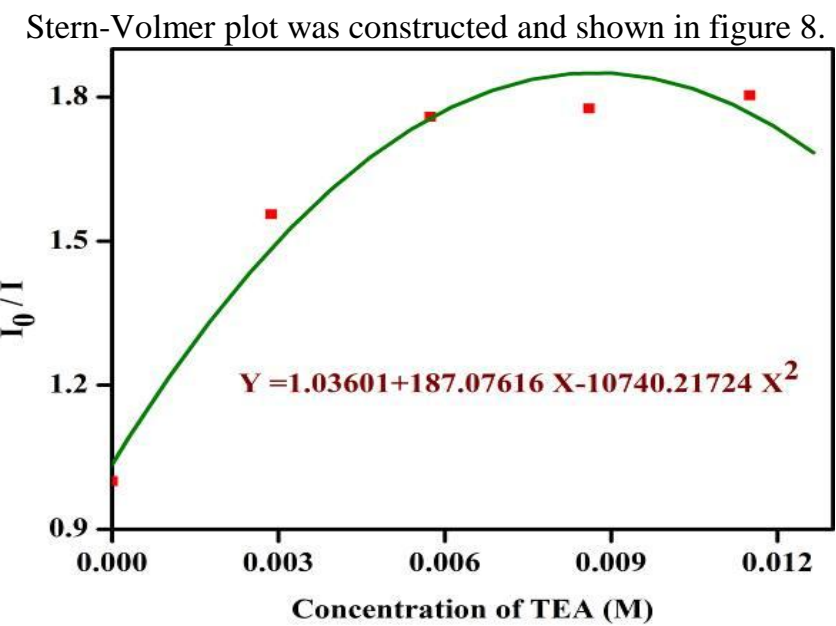

Figure 8: Stern-Volmer plot of 1:1 CdS quantum dots in AOT reverse micelles with triethyl amine 
A downward curvature was observed in the plot. This observation is also attributed to the static nature of the quenching process where the quencher molecules are present in the vicinity of the quantum dot surface.

Luminescence quenching studies were also carried out for 1:2 CdS quantum dots with $\mathrm{N}, \mathrm{N}$-dimethyl aniline and triethylamine. The luminescence quenching spectra and the Stern-Volmer plot for the DMA are given in figures $9 \& 10$ respectively. The figures 11 and 12 illustrate the luminescence quenching spectra and Stern-Volmer plot for the TEA. Downward curvature was observed in the Stern-Volmer plots for the quenchers' N, N-dimethyl aniline and triethyl amine, showing the static quenching process. This shows that the size of the quantum dot does not play much role in the quenching process, but only the quencher position in the micelle decides the quenching mode.

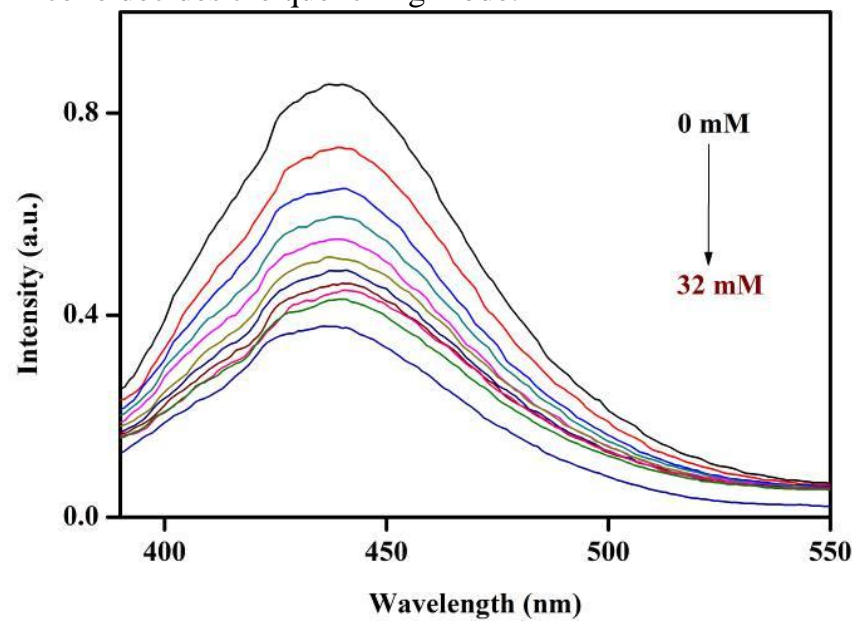

Figure 9: Luminescence emission spectrum of 1:2 CdS quantum dots in reverse micelles with various concentrations of $\mathrm{N}, \mathrm{N}$, dimethyl aniline. The concentration values are $0,3.15,6.31,9.46,12.6,15.7$, 18.9, 22.1, 25.2, 28.4, $31.5 \mathrm{mM}$

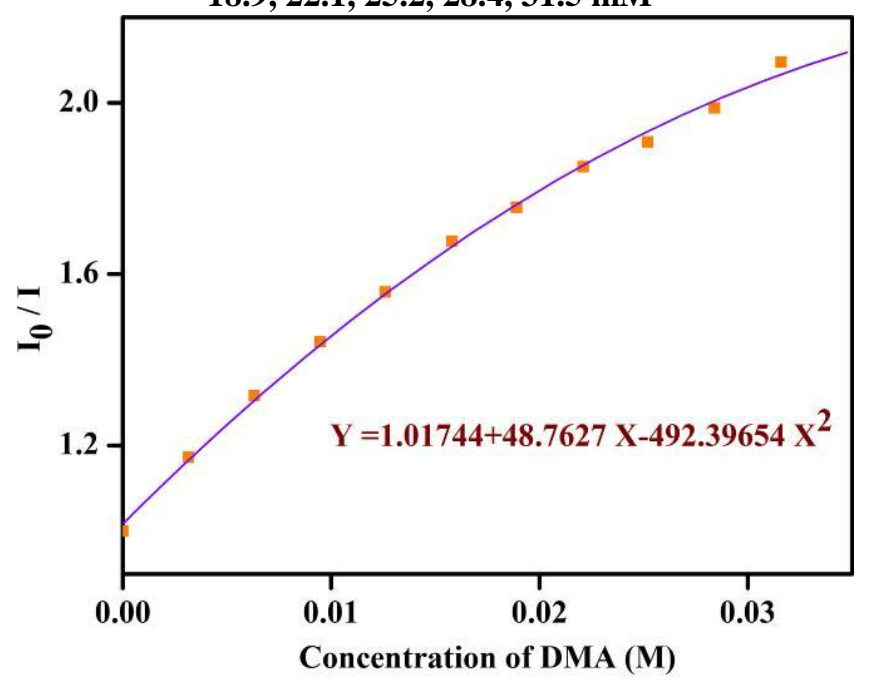

Figure 10: Stern Volmer plot of 1:2 CdS quantum dots in reverse micelles with $\mathbf{N}$, $\mathrm{N}$-dimethyl aniline

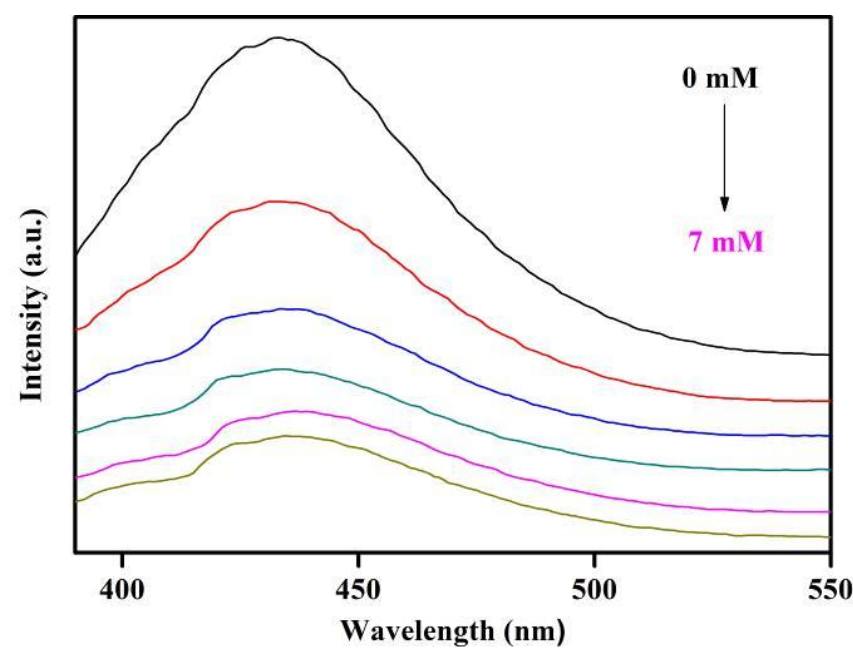

Figure 11: Luminescence emission spectrum of 1:2 CdS quantum dots in reverse micelles with various concentration of triethyl amine. The concentration values are $0,1.43,2.86,4.30,5.74,7.17 \mathrm{mM}$

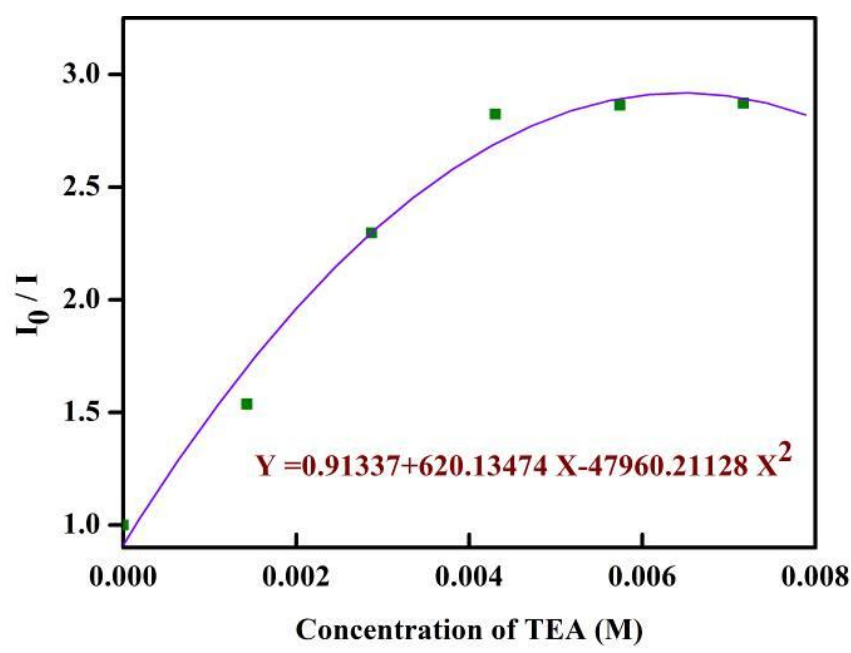

Figure 12: Stern Volmer plot of 1:2 CdS quantum dots in reverse micelles with triethyl amine

A scheme representing the position of the quencher molecules in the reverse micelle is given in scheme 

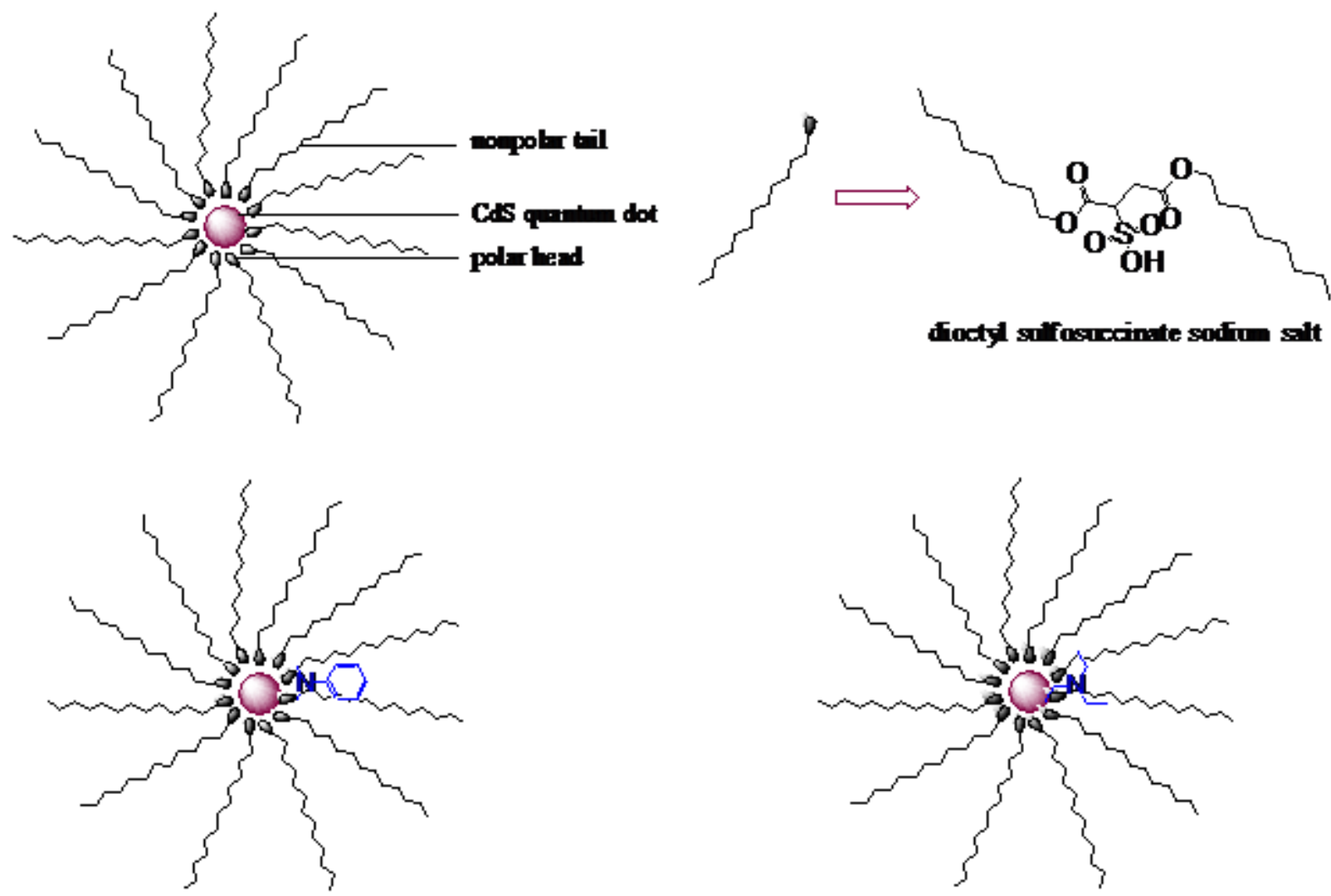

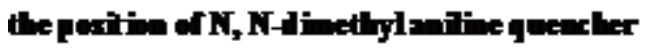

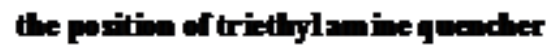

Scheme 1: The scheme represents the position of the quencher molecule in AOT reverse micelle.

\section{CONCLUSION}

The synthesis of CdS quantum dots was successfully accomplished AOT reverse micellar self-assemblies. The CdS quantum dots were synthesized with different precursor ratio. The luminescence quenching studies were performed with triethyl amine and N, N-dimethyl amine molecules. The study revealed that the luminescence quenching increases with increase in amine concentration. It is also observed that the size of the quantum dots varied with concentration of sulphide ions. It is concluded from the Stern-Volmer plots that the quenching process is static and also suggested that the quencher molecules to the quantum dot surface.

\section{ACKNOWLEDGEMNTS}

The authors sincerely thank the management of Kalasalingam Academy of Research and Education, Tamil Nadu, India for their constant encouragement and support and providing all the necessary facilities for carrying out this study. Authors also thank Vivekananda College, Madurai and University of Madras, Taramani campus, National center for Ultrafast Process, Chennai for carrying out abortion and emission analysis.

\section{REFERENCES}

1. M.L. Steigerwald and L.E. Brus, "Semiconductor crystallites: a class of large molecules", Acc. Chem. Res. vol. 23, 1990, pp. 183-188.

2. M. Nirmal and L.E. Brus, "Luminescence Photophysics in Semiconductor Nanocrystals", Acc. Chem. Res. vol. 32, 1999, pp. 407-414.

3. A.P. Alivisatos, "Perspectives on the Physical Chemistry of Semiconductor Nanocrystals", J. Phys. Chem. vol. 100, 1996, pp. 13226-13239.

4. C.J. Murphy and J.L. Coffer, "Quantum Dots: A Primer" Appl. Spectrosc. vol. 56, 2002, pp. 16A-27A.

5. V.I. Klimov, A.A. Mikhailovsky, Su Xu, A. Malko, J.A. Hollingsworth, C. A. Leatherdale, H.-J. Eisler and M. G. Bawendi, "Optical Gain and Stimulated Emission in Nanocrystal Quantum Dots", Science. vol. 290, 2000, pp. 314-317.

6. B.I. Lemon and R. M. Crooks, "Preparation and Characterization of Dendrimer-Encapsulated CdS Semiconductor Quantum Dots", J.Am. Chem. Soc. vol. 122, 2000,pp. 12886-12887.

7. W. Vogel, J. Urban, M. Kundu and S.K. Kulkarni, "Sphalerite-Wurtzite Intermediates in NanocrystallineCdS", Langmuir. vol. 13, 1997,pp. 827-832.

8. Y. Tian and J.H. Fendler, "Langmuir-Blodgett Film Formation from Fluorescence-Activated, Surfactant-Capped, Size-Selected CdS Nanoparticles Spread on Water Surfaces”, Chem. Mater. vol. 8, 1996, pp. 969-974.

9. Y-P. Sun, H.W. Rollins, "Preparation of polymer-protected semiconductor nanoparticles through the rapid expansion of supercritical fluid solution", Chem. Phys. Lett. vol. 288, 1998, pp. 585-588.

10. S. Gorer and R.M. Penner, "“Multipulse” Electrochemical/Chemical Synthesis of CdS/S Core/Shell Nanocrystals Exhibiting Ultranarrow Photoluminescence Emission Lines", J. Phys. Chem. B vol. 103, . 1999, pp. 5750-5753.

11. H. Ohde, M. Ohde, F. Bailey, H. Kim and C.M. Wai, "Water-in- $\mathrm{CO}_{2}$ Microemulsions as Nanoreactors for Synthesizing $\mathrm{CdS}$ and $\mathrm{ZnS}$ Nanoparticles in Supercritical $\mathrm{CO}_{2}$ ", Nano. Lett. vol. 2, 2002, pp. 721-724.

12. T. Dannhauser, M. O'Neil, K. Johansson, D. Whitten and G. McLendon, "Photophysics of quantized colloidal semiconductors. Dramatic luminescence enhancement by binding of simple amines", J. Phys. Chem. vol. 90, 1986, pp. 6074-6076.

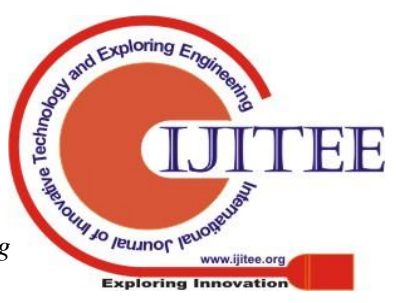




\section{Synthesis, Characterization and Photophysical Analysis of CDS Nanoparticles}

13. S. Logunov, T. Green, S. Marguet and M.A. El-Sayed. "Interfacial Carriers Dynamics of CdS Nanoparticles", J. Phys. Chem. A. vol. 102, 1998, pp. 5652-5658.

14. R.N. Bhargava, D. Gallagher, X. Hong and A. Nurmikko, "Optical properties of manganese-doped nanocrystals of ZnS", Phys. Rev. Lett. vol. 72, 1994, pp. 416-419.

15. R.N. Bhargava, "Doped nanocrystalline materials -Physics and applications", J. Lumin, vol. 70, 1996, pp. 85-94.

16. K.S. Narayan, A.G. Manoj, J. Nanda and D.D. Sarma, "Dual function hybrid polymer-nanoparticle devices", Appl. Phys. Lett. vol. 74, 1999, pp. 871-873.

17. Y. Yang, J. Hung, S. Liu and J. Shen, "Preparation, characterization and electroluminescence of $\mathrm{ZnS}$ nanocrystals in a polymer matrix", $J$. Mater. Chem. vol. 7, 1997, pp. 131-133.

18. V.L. Colvin, M.C. Schlamp and A.P. Alivisatos, "Light-emitting diodes made from cadmium selenide nanocrystals and a semiconducting polymer", Nature, vol. 370, 1994, pp. 354-357.

19. M.C. Schlamp, X. Peng and A.P. Alivisatos, "Improved efficiencies in light emitting diodes made with $\mathrm{CdSe}(\mathrm{CdS})$ core/shell type nanocrystals and a semiconducting polymer", J. Appl. Phys. vol. 82, 1997, pp. $5837-5842$.

20. M. Gao, C. Lesser, S. Kirstein, H. Möhwald, A.L. Rogach, and H. Weller, "Electroluminescence of different colors from polycation/CdTe nanocrystal self-assembled films", J.Appl. Phys vol. 87, . 2000, pp. 2297-2302

21. W.C. Chan and S. Nie, "Quantum Dot Bioconjugates for Ultrasensitive Nonisotopic Detection”, Science, vol. 281, 1998, pp. 2016-2018.

22. M.A. Lopez-Quintela, J. Rivas, "Chemical Reactions in Microemulsions: A Powerful Method to Obtain Ultrafine Particles", $J$. Colloid Interface Sci. vol. 158, 1993, pp. 446-451.

23. P. Lianos and J.K. Thomas, "Cadmium sulfide of small dimensions produced in inverted micelles", Chem. Phys. Lett. vol. 125, 1986, pp. 299-302.

24. D. Wu, X. Ge, Z. Zhang, M. Wang, and S. Zhang, "Novel one-step route for synthesizing CdS/polystyrene nanocomposite hollow spheres", Langmuir, vol. 20, 2004, pp. 5192-5195.

\section{AUTHORS PROFILE}

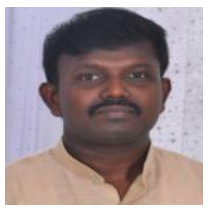

Sundaravel Balachandran received his doctorate in Chemistry from Anna University, Chennai, Tamil Nadu-India. His major area of research interest is heterogeneous catalysis. He is having about 14 publications to his credit.

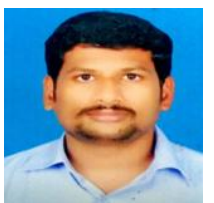

Ponnuchamy Singannan received his doctorate in Chemistry from Madurai Kamaraj University, Maurai, Tamil Nadu-India. His major area of research interest is synthesis of novel organic molecules for medicinal applications. He is having about 3 research articles and 2 patents to his credit.

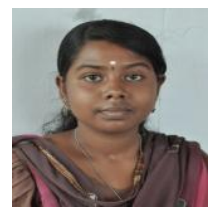

Anushiya Thiravium pursuing B.Sc. Chemistry in Kalasalingam Academy of Research and Education, Krishnankoil, Tamil Nadu-India. She was a member of INSA-SRFP-2019. 